\title{
Agudización de la pobreza del campesinado peruano y el subsidio al bienestar de la ciudad
}

\author{
Worsening poverty of the Peruvian peasantry and the city's welfare subsidy \\ Agravamento da pobreza do camponês peruano e subsídio previdenciário da cidade
}

\author{
Orlando Velásquez Benites \\ orlandovelasquez.ovb@gmail.com \\ https://orcid.org/0000-0001-5575-107X \\ Universidad César Vallejo, Trujillo, Perú
}

Artículo recibido 11 de marzo 2021 / Arbitrado y aceptado 29 de marzo 2021 / Publicado 04 de mayo 2021

\section{RESUMEN}

El artículo muestra que el bajo precio de los productos agrícolas garantiza el bienestar de las ciudades a expensas de los productores rurales porque se venden a un costo por debajo de su producción, agravando la pobreza del campesino peruano. Se inicia con la descripción, posicionamiento y análisis de la población campesina durante la construcción de la república, incidiendo en el maltrato y abandono de los campesinos en el país, buscando y conquistando mejores condiciones de vida, y afectando su lucha por la supervivencia y su vida. La metodología es Histórico Comparativo para la revisión bibliográfica del origen, ubicación y desarrollo de los agricultores, también es Etnográfico porque se utilizó datos del Ministerio de Agricultura. El resultado muestra la postergación y marginación del campesinado. Concluyendo que la pobreza del campesino peruano se agudiza por la asfixia del mercado porque sus productos están muy por debajo del costo de producción.

Palabras clave: Campesinado; mercado; pobreza; producción agropecuaria; subsidio

ABSTRACT

RESUMO

The article shows that the low price of agricultural products guarantees the well-being of the cities at the expense of rural producers because they are sold at a cost below their production, aggravating the poverty of the Peruvian peasant. It begins with the description, positioning and analysis of the peasant population during the construction of the republic, influencing the mistreatment and abandonment of peasants in the country, seeking and achieving better living conditions, and affecting their struggle for survival and their lifetime. The methodology is Historical Comparative for the bibliographic review of the origin, location and development of farmers, it is also ethnographic because data from the Ministry of Agriculture was used. The result shows the postponement and marginalization of the peasantry. Concluding that the poverty of the Peruvian peasant is exacerbated by the suffocation of the market because their products are well below the cost of production.

Key words: Peasant; Market; Poverty, Agricultural production; Subsidy
O artigo mostra que o baixo preço dos produtos agrícolas garante o bemestar das cidades em detrimento dos produtores rurais, pois são vendidos a um custo inferior à sua produção, agravando a pobreza do camponês peruano. Inicia-se com a descrição, posicionamento e análise da população camponesa durante a construção da república, influenciando os maus-tratos e abandono dos camponeses no país, buscando e alcançando melhores condições de vida, e afetando sua luta pela sobrevivência e sua vida. A metodologiaé Histórica Comparativa para a revisão bibliográfica sobre a origem, localização e desenvolvimento dos agricultores, também é etnográfica porque foram utilizados dados do Ministério da Agricultura. O resultado mostra o adiamento e a marginalização do campesinato. Concluindo que a pobreza do camponês peruano é agravada pela asfixia do mercado porque seus produtos estão bem abaixo do custo de produção.

Palavras-chave: Camponês; mercado; pobreza; produção agrícola; subsídio 


\section{INTRODUCCIÓN}

En los últimos diez años, políticos y académicos regionales, incluido Perú, han enfatizado el milagro de la economía peruana, el crecimiento económico, la baja inflación y la reducción de la pobreza. En este caso, observamos en el centro de distribución de alimentos que un kilogramo de papa se vende a 0.50 centavos al sol, el trigo se vende a 1 sol, y los precios de otros productos son muy bajos, la oferta es muy abundante y los precios también son muy bajos. Para la satisfacción del consumidor, nos preguntamos por qué siempre sentimos que los agricultores sufren y son pobres. Dicha constatación inspiró esta investigación para comprender una o más razones de la continua pobreza de la población rural, y la relación entre los precios de sus productos y el costo de producción, afectando el papel de los canales de comercialización y el estado. Para ello, utilizando métodos históricos comparativos para rastrear el proceso de construcción de la república y el tratamiento de la población campesina, los cambios en la propiedad de la tierra y el papel del Estado a través de la revisión de la literatura, el tratamiento de la población rural se posiciona en el libre mercado según la Constitución de 1993; así como el estudio de campo realizado en el Sur y la Sierra Norte Perú.

Los resultados del trabajo muestran que en comparación con los datos macroeconómicos oficiales, la pobreza de los agricultores peruanos se ha mantenido y agravado. La mayoría de los productores se ubican a una altura de más de 3.000 metros, plantando canastas populares, los principales productos de la papa blanca, Trigo, granos, en condiciones que no son propicias para su economía, sólo ha mejorado en las zonas bajas, el principal problema son los bajos precios de los productos agrícolas. Esta realidad es común en diferentes partes del país, salvo que él y su familia no son compensados por su trabajo, y los precios en estas áreas no les permiten pagar el monto mínimo de inversión. Esta realidad se complica cuando el país aplica los tabúes equivocados de la economía de mercado y no brinda asistencia técnica, apoyo crediticio y apoyo para la comercialización de sus productos, para que caigan en manos de mercados desfavorables y agraven su pobreza y conflictos.

\section{La población campesina de Perú}

Perú es un país históricamente agrario, las grandes civilizaciones que sentaron las bases de la sociedad peruana y alcanzaron el imperio Tahuantinsuyo vía Wari, Nazca, Paracas, Chavín, Tiahuanaco, Caral, Moche, Chimú, tuvieron su sustento en la agricultura, por lo que "el hombre peruano desde un principio fue un íntimo "Conectados a la tierra” (1). De ahí su cosmovisión, el marco ideológico simbólico, el culto, giraba en torno a la productividad del país. En este contexto, se refieren a la existencia de una deidad que posee bienes agrícolas y ganaderos, que entrega con su cariño a quienes son capaces de producirlos. En el mundo prehispánico, la tradición cultural, la religiosidad y la divinidad se basan en la producción agrícola y animal. La tierra, la pachamama, es el centro de la vida (2). La traducción al español de pachamama es 
"Madre Naturaleza". Afirma que al referimos a la pachamama no solo a la extensión limitada del planeta tierra, sino a todo lo que el hombre está y en su alrededor por encima y por debajo de él (3).

La colonia no fue la excepción, pese a la ambición del colonizador por los metales preciosos y la política negativa de privilegiar la importación de productos del viejo mundo, la agricultura siguió como el rubro principal del virreinato, a pesar que el régimen agrario colonial determinó la sustitución de una gran parte de las comunidades agrarias (4). La transición a la República y durante gran parte de su desarrollo hasta entrada la segunda mitad del siglo XX, la actividad agrícola y pecuaria continúa como el renglón productivo principal de la economía peruana, en correspondencia con una población predominantemente campesina, como se demuestra en la estadística Tabla 1.

En las últimas décadas del siglo anterior, la hacienda incorpora tecnología en la producción de caña de azúcar, algodón, arroz. Poco a poco se sacude del sistema de enganche, era una vil explotación del indígena arrancado de su lugar de origen por el enganchador que iba a los pueblos se la serranía y con engaños de mejoras económicas los llevaba a la hacienda, donde los esclavizaba al no poder pagar la suma de dinero que les entregaba en el "compromiso inicial con la complicidad de las autoridades locales (5). Era un campesino de la sierra de La Libertad o de Cajamarca que bajaba a pagar su deuda en las haciendas azucareras, la cual lo inmovilizaba y le quitaba su libertad de movimiento (6). Esté viraje obligado por las nuevas condiciones y la competencia internacional, fue acompañado por una legislación proclive a la clase terrateniente, en la importación de maquinaria, insumos y otros grandes privilegios como fue el caso del puerto Chicama en la Libertad, que fue cedido en exclusividad a la hacienda Casagrande. La ley de aguas le daba grandes ventajas para la producción de sus extensos territorios, en perjuicio de las comunidades y el campesinado en general, que padecía por la falta de riego, obligándolo a rematar sus tierras, que generalmente eran absorbidas por la hacienda.

El país desigual que construyó la República, tiene a la población urbana y los sectores poblacionales privilegiados como base de un Estado elitista, exclusivo. En tanto la gran masa campesina, siendo la mayoría de la población peruana, continúa marginada, alejada del oficialismo, hostigada y maltratada por los dueños del poder económico. En el Directorio de Comunidades Campesinas, afirman que éstas siguen "postergadas y desatendidas por el Estado peruano". Las estadísticas oficiales demuestran que hasta mediados de siglo, la población peruana era mayoritariamente campesina, más aún si la región de la sierra duplicaba la población de la costa, como se demuestra en la serie histórica de los censos del Instituto Nacional de Estadística e Informática. A ello se suma que la agricultura seguía siendo la base de la economía peruana, pues en ella descansaba no sólo la alimentación de la población, sino la ocupación de la población económicamente activa Perú. 
Tabla 1. Perú: Evolución de la población censada, según región natural.

\begin{tabular}{ccccccc}
\hline Región Natural & $\mathbf{1 9 4 0}$ & $\mathbf{1 9 6 1}$ & $\mathbf{1 9 7 2}$ & $\mathbf{1 9 9 3}$ & $\mathbf{2 0 0 7}$ & $\mathbf{2 0 1 7}$ \\
\hline Total & 6,207967 & 9,906746 & 13,538208 & $22,048,368$ & $27,412,157$ & 29,381884 \\
Costa & $1,759,573$ & $3,859,443$ & $6,242,993$ & $11,547,743$ & 14973,264 & $17,037,297$ \\
Sierra & 4,033952 & $5,182,093$ & $5,953,293$ & $7,668,359$ & $8,763,601$ & $8,268,183$ \\
Selva & 414,452 & 865,210 & $1,341,922$ & 2832,254 & $3,675,262$ & $4,076,404$ \\
\hline
\end{tabular}

Fuente: INEI. Censos Nacionales de Población y Vivienda - 2017 (7)

La Tabla muestra el proceso de desarrollo de la población peruana en cuanto a la composición por regiones y en consecuencia los cambios producidos en la urbanización como consecuencia de la migración del campo a la ciudad. Apenas hace poco más de siete décadas la población de la sierra era inmensamente mayoritaria, lo que demuestra que el campesinado en el cual se le considera a la comunidad campesina y nativa, representó la mayoría de la población durante los dos tercios de la República, lo que permite precisar las limitaciones de las políticas públicas de un Estado que gobernó para una minoría. La cosmovisión campesina heredada desde el pasado prehispánico, se mantenía en todo su vigor, porque ni la colonia, ni la República que replicó su modelo de explotación del indio, pudieron erradicar la riqueza cultural de su tradición. El ser humano crea su ideología desde sus orígenes que forman parte de su personalidad, al engendrar las costumbres, leyes, la civilización en una palabra (8).

El fenómeno migratorio desde la década del cincuenta, se debe precisamente al trato discriminatorio y racista contra la población andina comparable al análisis (9); y al abandono por parte del Estado. Sin embargo, las nuevas condiciones del país, el desarrollo de la competencia en el mercado internacional y las reglas de juego de la penetración capitalista, crea otras condiciones que hace insostenible la vida en el medio rural. A esta realidad se suman los mecanismos de atracción que la urbanización genera, arrancando a la familia o parte de ella hacia la ciudad para engrosar la oferta de mano de obra, la conformación de cinturones de miseria y el proceso acelerado de despoblamiento del campo. Aquí surge el gran problema de la moral y la respuesta cultural del indio. Interpretando la obra de Arguedas en la novela "el zorro de arriba y el zorro de abajo ", toma como escenario Chimbote, que "muestra el impulso pujante del mundo moderno que estrangula la moral y el comportamiento del indio, que le cambia de valores y de costumbres" (10). La población andina se asienta e irrumpe la ciudad con sus costumbres y patrones de vida (11).

El proceso acelerado de migración del campo a la ciudad, ha producido un cambio cualitativo en la composición de la población peruana. A diferencia de mediados de siglo, hoy segúnelcensodel2017,Perútieneunapoblación total de 31,826,018 millones de habitantes, siendo la población económicamente activa de 17,062,409 millones, de ella la costa tiene una población económicamente activa de 
$12,664,716$ millones, en tanto que la sierra se reduce a 4,118,029 millones (12). Si a esta cifra le agregamos que, en las mismas estadísticas de la población urbana, el censo arroja que 800,000 personas se dedican a la agricultura, tendremos un promedio de cinco millones de pobladores vinculados directamente al campo en costa, sierra y selva (13).

El Ministerio de Agricultura, publicó el directorio de comunidades campesinas, cuyas estadísticas arrojan un total de 7,267 organizaciones. Ese mismo año se publicó el directorio de comunidades nativas, arrojando un total de 2,166 organizaciones originarias. Si se analiza el universo muestral del III Censo Nacional de Comunidades Campesinas y el III Censo Nacional de Comunidades Nativas, la información estadística arroja 6,682 organizaciones comunales censadas. Por lo tanto, sia estacifrasedestaca conlainformación oficial de los Directorios de Comunidades, se registran en Perú 9,283 Comunidades, entre Campesinas y Nativas y si solo se han censado 6,682 , lo que indica que la información censal del Estado peruano no ha registrado a 2,601 Comunidades., Aproximadamente un tercio de organizaciones comunales quedaron fuera de las estadísticas censales.

Además, solo el mínimo de 60 familias por comunidad a un promedio de 6 personas por familia, no se habría censado a cerca de un millón de personas. En consecuencia, a los seis millones de pobladores de la zona rural, se debe sumar esta cantidad, arrojando un aproximado de siete millones de peruanos conformando la población rural. Si bien esta cifra es relativa, es importante para calcular la composición del campesinado, asociándola a la población rural, que, para los fines del presente análisis, permite contar con un horizonte más claro.

\section{El campesinado peruano antes y después de la Reforma Agraria}

Al largo período de explotación y adormecimiento del campesinado peruano, que en su mayoría se refugia en las zonas andinas y amazónicas, a partir de las primeras décadas del siglo $X X$, se crean otras condiciones sociales, políticas y económicas. El terrateniente se vio obligado a integrar desarrollos tecnológicos en el campo y en las fábricas, lo que permitió el aumento de áreas cultivables, realidad que cambió las relaciones en el campo ya que la fuerza de trabajo también tuvo que ser especializada, requiriéndose más trabajadores (14). Nacen los sindicatos se organizan federaciones $y$ centros, al mismo tiempo que nacen y se desarrollan los partidos aprista y socialista. La lucha por mejores condiciones laborales, la recuperación de la tierra y la reforma agraria se convierte en la consigna de la lucha del campesinado peruano.

Las décadas del 60 y el 70, fueron de constante efervescencia en el campo. La exigencia de apoyo técnico, créditos, vías de comunicación, irrigaciones, y en general un trato digno al hombre de campo, estuvo en el centro de la agenda del sector rural peruano. La guerra de guerrillas en algunos valles del sur y el norte Perú, dirigida por Luis de la Puente Uceda, en su condición de 
Comandante General, entre los años 1963 y 1965, abalando una reforma agraria inmediata terminando con su muerte. Los últimos años del gobierno de Belaúnde fueron de tomas de tierras, carreteras, desgobierno, por un campesinado que exigía cada vez con más fuerza la reforma agraria, siendo destituido por el General Velasco, que instala un "Gobierno Revolucionario de la Fuerza Armada", siendo su principal medida la reforma agraria radical, expropiando las grandes haciendas, aunque según, la reforma Agraria, no significó la redistribución de la tierra entre los campesinos, porque eso ocurrió sólo para los campesinos que labraban la tierra, porque las tierras de la hacienda se entregó a sus trabajadores bajo la modalidad de empresas asociativas, cambiando la estructura agraria en Perú (15).

Después de una bonanza del agro asociativo, se produce la parcelación individual de las empresas agrarias, constituidas como Cooperativas agrarias, Sociedades Agrícolas de Interés Social, Grupos Campesinos, respondiendo a la tradición cultural de asumir la conducción de la propiedad de la tierra en forma individual. Inicia el desmontaje de la Reforma Agraria, alentado desde el Gobierno, pone término a la Reforma Agraria, fortaleciendo la pequeña propiedad (16). Este período coincide con el ataque de Sendero Luminoso, atacan a la empresa asociativa, las poblaciones migran en masa para huir de la violencia (17). La comunidad campesina como tal se conservó porque existía una tradición cultural colectiva que fortaleció la reforma agraria mediante la anexión de nuevas tierras y la titulación y delimitación territorial.
A pesar del fracaso de la Reforma Agraria, se produjo un cambio cualitativo en la tenencia de la tierra. La expropiación de la gran hacienda y el latifundio tradicional, dio paso a la posesión y propiedad del campesino, convertido en micro, pequeño y mediano agricultor. Las políticas liberales y neoliberales de los gobiernos sucesivos, en particular el decenio fujimorista, no sólo desmontaron la Reforma Agraria, sino que crearon condiciones para la reconcentración de la tierra, como se hizo con los grandes complejos azucareros, cuyas medidas gubernamentales, permitieron arrebatar la tierra a sus legítimos propietarios, entregando a las grandes capitales. Este proceso de reconcentración se alimentó con las políticas oficiales del Sector Agricultura, que promovió la exclusión del campesino o el pequeño agricultor en la adjudicación de tierras en los grandes proyectos de Irrigación, privilegiando a la empresa agroindustrial, convertido hoy en el nuevo enclave latifundista en el agro peruano. Pese a la millonaria inversión del Estado peruano en estos proyectos, se legisla porque unos pocos adquieran las tierras.

Los inmensos proyectos de irrigación en Majes, Arequipa, Chinecas en Ancash, Chavimochic en la Libertad, Gallito Ciego entre La Libertad y Cajamarca, Tinajones y Olmos en Lambayeque, Chira Piura en los valles de Sullana y Piura, y recientemente el Alto Piura, solo han favorecido a grandes empresas agroindustriales. Son los nuevos terratenientes, que no solo han acaparado las mejores tierras de la costa y de la sierra, sino 
que, siguiendo los viejos métodos feudales, arrinconaron a los pequeños agricultores, los dejaron sin agua, créditos y mercado y los obligaron a rematarles o entregarle sus tierras a cambio de salarios, cuyo sistema hoy ha generado huelgas y toma de carreteras.

\section{Producción, productividad y rol de los organismos públicos de apoyo al sector agropecuario}

El Estado a través del Banco Agrario, el Ministerio de Agricultura, fomentaba la producción agrícola y pecuaria. El Centro de Investigación y Promoción Agropecuaria (CIPA) jugó un rol muy importante en la productividad del campo. La producción permitía el autoabastecimiento de la canasta familiar. Después de la Reforma Agraria, el Estado incrementó el apoyo al campo. Se crea la Empresa Nacional de Comercialización de Insumos(ENCl), laEmpresa deComercialización de Arroz Sociedad Anónima (ECASA), que eran empresas estatales encargadas de adquirir el sobrante de la producción campesina. Se fortaleció el Banco Agrario y el CIPA, da paso al Instituto Nacional de Investigación Agraria (INIA), para garantizar un mayor apoyo técnico a la agricultura. La creación del Programa de Reactivación Agropecuaria y Seguridad Alimentaria (PRESA) redactado en los primeros meses de 1986, que sentó las bases de la política agrícola del gobierno aprista, que reformuló la $\mathrm{ENCl}$, aplicó aranceles a los productos importados y creó un sistema agropecuario (18).
Entre los 60 y 80's, hubo relativa estabilidad en el campo, a pesar de las políticas anti agrarias del Gobierno y el accionar abusivo del hacendado que afectaba al campesinado. El segundo gobierno de Belaunde y de García, empezaron el desmontaje de la Reforma Agraria, propiciaron la parcelación individual de las tierras, fueron retirando la política de subsidios, inician un gradual abandono de la producción agropecuaria. Fujimori en su gobierno de los 90, terminó el desmontaje de la Reforma Agraria, los subsidios, el apoyo técnico, en concordancia con la Constitución de 1993, promovida por su gobierno, imponiendo una férrea política neoliberal, incluye el libre mercado y en consecuencia deja la producción agropecuaria en las garras del mercantilismo, con grave perjuicio a la familia campesina, cuya situación económica se agrava, especialmente por la venta de sus productos por debajo de sus costos de producción, con el empobrecimiento del campesinado y el incremento de la migración del campo a la ciudad.

El CIPA, el INIA, ENCI, ECASA, el Banco Agrario pasaron a la historia y en una falsa concepción de libre mercado dejaron la producción campesina a expensas del comercio capitalista. Los niveles de producción alcanzados en los años anteriores, que permitían el autoabastecimiento nacional, empezaron a decaer sustancialmente. El Ministerio de Agricultura abandonó su rol de regular y controlar la producción agrícola. El liberalismo oficialista retiró todos los subsidios al campo, tipificando esta fortaleza 
como acciones "paternalistas y negativas para el desarrollo" de la producción, en aplicación con la economía de mercado.

Actualmente el sector rural está en completo abandono, no existe un programa ni proyecto de desarrollo agropecuario. El Ministerio de agricultura, ha dejado de acompañar a la producción agrícola y pecuaria. Existen algunas irrigaciones que privilegian la empresa agroindustrial, en perjuicio del productor de pan llevar, frutas, tubérculos, granos, hortalizas y demás productos básicos para la alimentación popular, que hoy se importan mayormente. Los programas de embalsamiento de agua en algunos sectores del ande, son aislados y no son parte de una política agraria permanente. No existe una política de apoyo técnico, crediticio ni de planificación agropecuaria, como se aprecia en los períodos de escasez y sobreproducción que perjudican gravemente al productor del campo.

\section{Comercialización y mercado de la producción agropecuaria}

Perú, hace décadas que adoptó el modelo económico de libre mercado. Las Constitución de 1993, determina con claridad este rumbo e incluso ha establecido las reglas para garantizarlo. El art. 58 sanciona que "la iniciativa privada es libre. Se ejerce en una economía social de mercado". El art. 61, determina que "El Estado facilita y garantiza la libre competencia". Incluso el extremismo de la Carta Magna precisa que" Mediante Contrato Ley, el Estado puede establecer garantías y otorgar seguridades", de tal manera que los contratos "No pueden ser modificados legislativamente". En este marco, el micro, el pequeño y el mediano agricultor, se encuentran a la deriva e impotencia para enfrentar las reglas de juego del mercado.

La pobreza de la población rural es estructural y corresponde al modelo de desarrollo de la sociedad peruana, a su construcción, a los procesos instituidos desde la fundación de la República. Perú se ve como un país con crecimiento sostenido desde hace tres décadas, sin embargo, el campesinado parece ajeno a este fenómeno. En el 2016, el 44\% de los pobladores rurales se hallan en situación de pobreza, tres veces más a la pobreza en zonas urbanas. Esta situación confirma la tesis de que el crecimiento económico peruano, celebrado por la mayoría de los economistas y alabado por gran parte de la clase política, no incluye al sector rural (19).

\section{La población campesina y la asfixia del mercado}

Del análisis de la tabla 1, del INEI, del 2017, se infiere que apenas hace 5 a 7 décadas era la población rural mayoritaria en la sociedad peruana. La producción agropecuaria es la base de la economía nacional, desde tiempos prehispánicos. La canasta familiar proviene de la producción nacional. Sin embargo, el desmontaje de la Reforma Agraria y el abandono al agro, pone la producción del campo en constante riesgo. Las grandes obras de regadío, que abarcan cientos de miles de acres en la costa y parte de la sierra, se están 
tomando los nuevos capitalistas porque la gran mayoría de los terrenos de los proyectos hidroeléctricos han sido adquiridos por grandes corporaciones, nuevos propietarios sumados a los que se apoderaron de las empresas azucareras, relanzando el viejo latifundismo con rostro moderno, cuya producción se dirige al mercado exterior y fomenta la importación de productos de consumo popular.

Los nuevos terratenientes, priorizan la producción de artículos agroindustriales para la exportación, alentados por el Estado peruano, sacrificando la producción de artículos de la alimentación popular. Por los años 90, Casagrande, Cartavio, Laredo en la Libertad; Tumán, Cayaltí, Pomalca, y Pucalá en Lambayeque; San Jacinto en Ancash; Andahuasi y Paramonga en Lima; Chucarapi en Arequipa, destinaban un porcentaje entre el 10 y el $20 \%$ a la producción de pan llevar. Cuando estas empresas son "regaladas por el Estado" al capitalista, éstas dejan de producir productos para el consumo popular. La misma dirección siguen las grandes empresas agroindustriales absorbiendo a micro y pequeños productores (20).

En la costa, el micro y pequeño productor, sobrevivientes de la Reforma Agraria, sufre por el agua, pese a que existe. La gran propiedad tiene la preferencia, además que se prioriza la producción agroindustrial. El cultivo de frutales, hortalizas, tubérculos y granos se encarecen, por el problema del agua, los abonos, los pesticidas, la falta de ayuda técnica y el crédito. En la sierra, la situación es peor, porque la mayor parte de su producción está supeditada a las temporadas de lluvias, que generalmente son irregulares. No existe infraestructura agrícola, vías de acceso dignas, pequeñas irrigaciones, crédito; tampoco ayuda técnica, incentivos a la producción. Por lo general la producción agrícola y pecuaria es determinada por la estación lluviosa y prácticas tradicionales.

En los valles costeños del Norte del Perú, la producción de mango, limón, ciruela, palto, maíz y granos, es impredecible. Hay años en que la producción de mango en Piura es tan abundante que los agricultores prefieren dejarlos caer y perder, antes de cosecharlos, cuyo precio es de un sol la caja de 20 Kilogramos Igual la ciruela y otros frutales. En cuanto a los granos y tubérculos, ocurre igual en períodos lluviosos, cuyo abaratamiento es tal, que no cubren los costos de producción, pese a que el trabajo de la familia no se considera. Esto ocurre con la siembra de papa y otros tubérculos, granos, menestras, así como la producción de ganado, leche. En los valles de la sierra de la Libertad, Ancash, Cajamarca, El Centro, Huancayo y el Sur Perú. El campesino andino recrea las ferias dominicales, donde comercializa directamente parte de su producción, para contrarrestar los efectos negativos del mercado insuficiente.

El 2019, cercano a la temporada de cosechas (mayo-junio), se hizo trabajo de campo en Puno, Huancayo y la Libertad (provincias andinas). Igualmente, en las costas de Piura y la Libertad. El resultado fue la insatisfacción de los pequeños productores agropecuarios sobre los precios del mercado. 
Coincidieron en afirmar que no respondían a los costos de producción, al esfuerzo de la familia campesina que desde la siembra, cuidado y cosecha realizan para poner su producto en el mercado y obtener lo necesario para vivir. (21)

Con el apoyo de ingenieros de las Direcciones de Estadística Agraria de las Direcciones Regionales de Puno y la Libertad, se construyó la cadena de comercialización: productor- distribuidor-mayorista-minoristapúblico consumidor. La cadena más directa. En otros casos más larga: productorintermediario o financista que compra la cosecha-distribuidor-mayorista-distribuidor local-minorista-público consumidor. La papa, el tomate, la cebolla, el mango, el limón y una gran cantidad de productos agrícolas pasan por estas cadenas, existiendo una enorme diferencia entre el precio del producto en chacra y el precio final de venta al público. En estos casos el campesino no recupera su inversión, aparte que tampoco se valora su trabajo, el de su familia, cuyo horario supera las doce horas diarias, incluyendo domingos y feriados.

\section{El falso tabú del subsidio al campesinado}

Por los antecedentes, se deja claro que políticas agrarias en favor del campo, no fueron producto de un cambio en la concepción del campesinado, sino por las luchas de éste, que exigió apoyo técnico, crediticio, subsidio a la producción, vías de comunicación, precios justos. Es la etapa en que el Gobierno, por las luchas del campesinado, recoge las demandas del agro y establece un sistema de incentivo al sector agropecuario, como se ha precisado anteriormente. Esta política relativamente proteccionista termina con la promulgación de la Constitución Política de 1993, que con la economía de mercado, retira los organismos de apoyo al agro, los subsidios y la protección de los excedentes de la producción del campo, entre otras medidas que terminaron con asfixiar al agro.

Ellosignificóqueel Ministerio deAgricultura deje de apoyar al agricultor con asistencia técnica en el campo, transferencia tecnológica, semillas mejoradas, infraestructura agrícola, titulación, planificación de la producción, para racionalizar las siembras, evitando la voracidad de la intermediación, con ferias, compra de los excedentes para los programas sociales. El subsidio a la producción fue el respaldo del estado para alcanzar un equilibrio entre la producción y los precios. No fue la entrega ni el regalo de dinero, sino la compensación al campesino por su esfuerzo en producir en adversas condiciones y abastecer con alimentos al grueso de la población, predominantemente urbana. (22).

En las regiones de Puno, el Centro y la Sierra de la Libertad, se demuestra que la aplicación de la política del libre mercado en el campo, es un absoluto desatino. La producción agropecuaria en Perú se hace en precarias condiciones, porque no hay vías de comunicación adecuadas, incluso la carretera central que es la principal vía a la sierra central Perú, está tan congestionada que solo para ir de Huancayo a Lima, es una larga procesión de 
muchísimas horas y que en período de lluvias se obstruye o paraliza semanas o meses, con graves perjuicios para el productor. En Puno, es una aventura y un peligro constante incluso para la vida. En la sierra de la Libertad, hay provincias enteras aisladas como Pataz y Bolívar. No hay agua y la mayoría de las siembras está condicionada a la irregularidad de los períodos lluviosos. Los abonos, semillas, pesticidas, insumos agrícolas son escasos y caros (23). En suma, los ortodoxos, quieren imponer en estas condiciones las leyes del mercado, fundamentalismo que no resiste ningún análisis racional. La imposición de la política de mercado, condena al campesino a vender su producción agropecuaria supeditada a la voracidad de la oferta y la demanda. No existen reglas claras en los volúmenes y flujos de producción, la falta de apoyo deja al productor en manos de intermediarios, de tal manera que siempre está obligado a vender sus productos, muy por debajo de sus costos de producción.

\section{Abandono y pobreza estructural del campesinado peruano}

La inversión pública en áreas rurales aumentó de 1.140 millones en 2002 a 7.087 millones en 2010 y que la inversión en infraestructura de riego y vías de comunicación se ha multiplicado por diez a la fecha (24). Sin embargo, esta inversión no se aprecia en un recorrido por Puno y especialmente en la Sierra de La Libertad. Es peor aún en regiones de Madre de Dios, Apurímac, Huancavelica, entre otras. Esta inversión no refleja el bienestar de los tramos más pobres de la costa, la Sierra y Amazonía, incluidas las comunidades rurales e indígenas. Las cifras se centran en los canales de comunicación de algunas regiones muy específicas, pero no en las provincias o ciudades remotas que aún no están integradas de manera sostenible en la política estatal.

El problema agrario parte de la inversión rural, es la puesta en marcha de las grandes irrigaciones, que benefician a los macro proyectos agropecuarios (la nueva clase latifundista) y que han perjudicado al pequeño agricultor, absorbido por la empresa agroindustrial (25). Hoy parte de sus tierras han pasado a engrosar los grandes fundos de espárragos, arándanos y otros productos para exportación, convirtiéndose en asalariados. La mayor inversión es en la costa y las partes bajas de la sierra, no así en los niveles a partir de los tres mil metros de altura, donde están los terrenos de los más pobres, que incluso los proyectos de pequeñas irrigaciones, promovidos por los agricultores con relativo apoyo del Sector Agrario, no llegan o no responden a las condiciones geográficas y climatológicas (26).

El gran problema que afronta el campesino, es que mayormente tiene parcelas muy pequeñas y dispersas (minifundio). La fragmentación de la tierra no le permite programar su producción y supeditarse a las lluvias, los períodos estacionales, posibles plagas y la dependencia del intermediario que le adelanta el pago para la siembra, porque el crédito bancario, casi siempre le es lejano. Los intercambios en el mercado están sujetos 
a riesgo en un entorno de incertidumbre donde prevalece la información imperfecta. Los bancos discriminan a los pequeños agricultores, que marginados del mercado de crédito según la lógica del banco, dejando en las garras del intermediario.

La cadena productiva, de acuerdo a la lógica del trabajo, empieza por el campesino, que es el auténtico productor y termina en él, como la víctima de un proceso viciado y perjudicial. El campesino, como se ha demostrado en la cadena del mercado de la producción agraria, cultiva sus tierras en condiciones adversas. Toda la familia participa en el cultivo, cuidado, mantenimiento y cosecha del producto, pero por las leyes del mercado y la usura que aún campea en este medio, nunca o casi nunca cubre sus costos de producción, salvo en algunos productos de las partes medias y bajas de la sierra. Al final, el capital usurario es el gran beneficiario, el Estado el cómplice y el consumidor de la ciudad el favorecido, pues gran parte de los productos agrícolas que provienen de esas zonas, no tienen precios reales, están por debajo de sus costos, de ahí que el bienestar de la ciudad es a costa de la pobreza de la familia campesina.

\section{MATERIALES Y MÉTODOS}

A través del método histórico comparativo, se ha seguido el comportamiento de los precios a través del tiempo, incidiendo en las tres últimas décadas, después del retiro de subsidios. La comprensión de las cuatro regiones de Piura, La Libertad, el Centro y Puno, ha permitido realizar un nivel de comparación en el precio de sus productos en el mercado, a partir de las variables costo de producción y precio de mercado, resultando que la constante se repite. El trabajo de campo ha permitido verificar IN SITU, que la venta de sus productos de chacra, especialmente de las zonas alto andinas por encima de los 3 mil metros se venden por debajo de los costos de producción, por lo que el trabajo de la familia, que siempre interviene en el proceso productivo, no es retribuido, recompensado, agudizando las carencias y la imposibilidad de cubrir sus necesidades básicas e incluso la reposición de las semillas para la futura siembra.

El método etnográfico, permitió constatar la dimensión del problema, que los mecanismos del mercado para sus productos se convierten en una rueda inevitable, lo cual genera la agudización de la pobreza. Esto porque en el campo se verificó que, ante la necesidad de afrontar nuevas siembras, porque tiene que atender el periodo lluvioso el campesino cae en las redes del usurero, que muchas veces es el propio comerciante o distribuidor que le entrega semilla o dinero para abonos y pesticidas, sometiéndolo a sus intereses y complicando la reducción de precios, atrapado por los condicionamientos preestablecidos. Las fuentes directas son las Direcciones Agrarias, hoy Gerencias Regionales del Ministerio de Agricultura, y en otros casos las Direcciones de Estadística de dichas Gerencias, lo cual ha ocurrido en las dependencias de Piura, La Libertad, el Centro y Puno. Igualmente siguiendo la metodología etnográfica, se ha caminado 
con los técnicos de campo de dichas oficinas, toda vez que ellos manipulan la información de producción y precios y están en contacto directo con el productor o campesino, siendo ellos los principales informantes.

\section{RESULTADOS}

Resulto fundamental el recabo de información desde las gerencias regionales del Ministerio de Agricultura, y las direcciones de estadística de dichas Gerencias. Ello permitió corroborar que desde siempre el campesino productor agrícola es el que garantiza el sostenimiento con sus productos en las ciudades, sin embargo, son los más perjudicados. La cadena productiva, inicia con el campesino, debido a que es identificado como el auténtico productor y termina en él, como la víctima de un proceso viciado y perjudicial, asfixiado por la imposición del mercado liberal y las garras de intermediario. Finalmente el desinterés del estado desde tiempos inmemoriales agudiza la pobreza del campesino peruano.

\section{DISCUSIÓN}

Esta investigación tuvo su esencia en analizar la pobreza extendida del campesino peruano a través del tiempo y de muchos gobiernos que en su afán, disque, de generar políticas de mejora al auténtico productor, más al contrario han terminado perjudicando, promoviendo estrategias de carácter demagógico propiciado siempre por grupos de poder económico que lucran perjudicando al campesino.
En un informe sobre la inversión pública en áreas rurales numéricamente se observa que va mejorando el sistema. Sin embargo, la pobreza rural es de carácter estructural debido a que no se aprecia de la misma manera en otras regiones Perú (17).

Los campesinos productores se encuentran en una situación de extrema pobreza, confirmando la tesis de que el crecimiento económico peruano, celebrado siempre por los economistas, impulsados por grupos de poder económico y político, no incluye con al sector rural, por lo que consideramos como una falta de sinceramiento en el manejo equitativo de la economía peruana (16). Los autores referidos en el presente artículo coinciden con el planteamiento de fondo del mismo. Lo que significa que se debe promover nuevas estrategias, dejando de lado la demagogia política y la usura económica, para desarrollar una sociedad justa equilibrada y equitativa para todos.

\section{CONCLUSIONES}

En base a los abordajes, se concluye:

Durante dos tercios de existencia de la República, la población campesina fue ampliamente mayoritaria, triplicando a la población de la costa, por lo que su exclusión de las políticas del Estado, son la causa de la pobreza estructural del país, de ahí que a pesar que hoy la realidad cambió y sólo la cuarta parte de la población peruana pertenece al área rural, la postergación continúa y se ha extendido a los cinturones de pobreza en la capital peruana y en las principales capitales regionales. 
La desatención de la población rural por parte del Estado peruano, la carencia de apoyo técnico, crediticio, vías de acceso y el problema del agua, continúan como parte de la política de exclusión, por lo que el problema campesino sigue sin resolver. Esta realidad se agudiza por la voracidad del mercado, que lo estrangula, al obligarlo a vender sus productos por debajo de los costos de producción. Por lo que no existe un proyecto de desarrollo agrario en Perú.

La postergación y la pobreza del campesinado peruano es estructural, que tiene su causa en la construcción desigual de la República, al posponer los derechos y la participación de la población originaria, la comunidad y el campesinado en general, situación que aún se mantiene en el aniversario del BICENTENARIO, con una Nación no inclusiva y que ha permitido que millones de peruanos de la Amazonía y las zonas altoandinas, construyan sus propias nacionalidades, posponiendo la esperanza republicana de construir un Perú justo e igualitario.

\section{REFERENCIAS BIBLIOGRÁFICAS}

1. Velásquez $\mathrm{O}$. Nuevo tipo de tenencia de la tierra en Perú. Universidad Nacional de Trujillo. 1996

2. Cáceres O. Martínez N. Los movimientos sociales en Puno. Mesianismo 1700-1750, Universidad Nacional Federico Villarreal. 2013

3. Mejía M. La Cosmovisión Andina y las categorías quechuas como fundamentos para una filosofía peruana y de América Latina. TEQSE. Universidad Ricardo Palma. Editorial Universitaria. 2011

4. Mariátegui J. 7 Ensayos de interpretación de la realidad peruana. Editorial Minerva. 1972
5. Klaren P. Formación de las haciendas azucareras y los orígenes del Apra. Colecciones Perú problema No 5. Instituto de estudios peruanos. IEP. 1976

6. Burga M. La hacienda en Perú. 1950-1976. Evidencias y Método de tierra y sociedad. Fondo Editorial. Lima Perú. 1978

7. INEI. Censo Nacional de Comunidades Campesinas. 2017

8. Pérez A. La Telesis social y la raza india. En Teoría de la Cultura Nacional. Banco de Reserva del Ecuador. 1986

9. Bustamante A. Migraciones contemporáneas. Formas de xenofobia en el caso francés, ETHNOS. 1(1). Facultad de Ciencias Sociales. Universidad Nacional Mayor de San Marcos. 2020

10. Castro A. Perú, un proyecto moderno. Pontificia Universidad Católica dPerú. 1994

11. Matos Mar. Una vida apasionada por la pluralidad social y cultural dPerú. Consultado el 7 de agosto de 2015.

12. Instituto Nacional de Estadística e Informática. Censos Nacionales. 2017

13. INEI. Censo Nacional de Comunidades Nativas. 2017

14. Helfgott $S$. El cultivo de la caña de azúcar en la costa peruana. Universidad Nacional Agraria La Molina. 1997.

15. Hall Ingrid. La reforma Agraria, entre memoria y olvido. Antropología. Versión impresa Diciembre 2013. Revista Scielo Perú. 2013;31(31).

16. Mejía J. De la Reforma Agraria a la promoción agropecuaria. Editorial Tiempo Presente. 1980.

17. Lemlij M. Millones L. Memoria, Imagen y Violencia. Apuntes Sobre Perú Andino. SIDEA. 2020.

18. Escobal J. Políticas de precios y subsidios agrícolas: impacto macroeconómico y sectorial, Perú 1985-1988. Documento de Trabajo No 5. Grupo de Análisis para el desarrollo. GRADE. 1989. 
19. Trivelli C. Urrutia C. Crecimiento y Reducción de la Pobreza, en Desigualdad y Pobreza. IEP. 2020.

20. Instituto Del Bien Común. Directorio de Comunidades Campesinas del Perú. Edición CEPES. 2016.

21. Ramírez, J. La Pobreza de los habitantes en zonas rurales. Semana Rural. 2019.

22. Älvarez, M. La Doctrina del Mercado Libre desde una perspectiva política. http://www. scielo.org.mx/pdf/polis/v15n1/2594-0686polis-15-01-143.pdf. 2019.
23. Ramírez J. La Pobreza de los habitantes en zonas rurales. Semana Rural. 2019

24. Aldama, U. Los ingresos de los peruanos de menores recursos en un contexto de alto crecimiento, en Desigualdad y Pobreza. IEP. Instituto de Estudios peruanos. 2020.

25. Figueroa A. y Altamirano T. Exclusión Social y Desigualdad en Perú. OIT. Oficina Regional para América Latina y el Caribe. 1996.

26. Jaramillo J. (2020) ¿Pobreza en el siglo XXI? Diario El Peruano. https://elperuano.pe/ noticia/101366-pobreza-en-el-siglo-xxi. 